Revue des patrimoines

46 | 2022

Le patrimoine de la Justice

\title{
L'hôtel de Bourvallais, place Vendôme : symbole patrimonial du ministère de la Justice
}

The hôtel de Bourvallais place Vendôme: heritage symbol of the ministry of Justice

Clémence Pau

\section{CpenEdition}

Journals

Édition électronique

URL : https://journals.openedition.org/insitu/33807

DOI : 10.4000/insitu.33807

ISSN : 1630-7305

Éditeur

Ministère de la Culture

Référence électronique

Clémence Pau, «L'hôtel de Bourvallais, place Vendôme : symbole patrimonial du ministère de la Justice », In Situ [En ligne], 46 | 2022, mis en ligne le 12 janvier 2022, consulté le 03 février 2022. URL http://journals.openedition.org/insitu/33807 ; DOI : https://doi.org/10.4000/insitu.33807

Ce document a été généré automatiquement le 3 février 2022

\section{(1) $\Theta$}

In Situ Revues des patrimoines est mis à disposition selon les termes de la licence Creative Commons Attribution - Pas d'Utilisation Commerciale - Pas de Modification 4.0 International. 


\title{
L'hôtel de Bourvallais, place Vendôme : symbole patrimonial du ministère de la Justice
}

The hôtel de Bourvallais place Vendôme: heritage symbol of the ministry of Justice

\author{
Clémence Pau
}

1 L'hôtel de Bourvallais, situé aux $\mathrm{n}^{\text {os }} 11$ et 13 de la place Vendôme à Paris, occupe une place toute particulière dans l'histoire patrimoniale de nos institutions ${ }^{1}$. En effet, en dépit des révolutions et des coups d'État qui ont jalonné l'histoire de la France contemporaine, la demeure n'a cessé d'abriter, depuis 1718, la Chancellerie de France puis le ministère de la Justice. Cet édifice, qui est à la fois le premier et le plus ancien hôtel ministériel de la capitale, constitue donc un exemple remarquable de la pérennité des lieux de pouvoir à Paris. En associant espace de vie et lieu de travail, l'hôtel de Bourvallais incarne également l'archétype même du "ministère » tel qu'on le définit depuis le XIX ${ }^{e}$ siècle, à savoir un «lieu où sont établis les bureaux d'un ministère, [...] [et] l'hôtel destiné à l'habitation d'un ministre ${ }^{2}$ ». Fort de ce double héritage historique et politique, l'hôtel de la place Vendôme revêt de nos jours un prestige d'autant plus grand que l'édifice et ses décors constituent un patrimoine architectural exceptionnel pour la Justice.

2 Le principal objectif de cet article est donc de revenir sur le processus de patrimonialisation de l'hôtel de Bourvallais, commencé dès le milieu du XIx $\mathrm{x}^{\mathrm{e}}$ siècle et achevé au début des années 1990. En retraçant rapidement l'histoire de l'édifice et en analysant les décors encore en place de nos jours, nous reviendrons ainsi sur les principales étapes qui ont mené à la protection et au classement de l'hôtel de Bourvallais et de ses décors au titre des monuments historiques au $\mathrm{xx}^{\mathrm{e}}$ siècle. 


\section{L'hôtel de Bourvallais : un bâtiment historique}

3 C'est le 5 septembre 1718 que, par un arrêt du Conseil du roi, l'hôtel de Bourvallais fut officiellement affecté à la Chancellerie de France ${ }^{3}$. Cette décision, loin d'être anodine, revêtait au contraire une importance toute particulière dans le processus de sédentarisation des institutions royales dans la capitale ${ }^{4}$. Jusqu'à cette date en effet, le chancelier vivait et tenait audience dans son propre hôtel lorsqu'il séjournait dans la capitale. La Chancellerie de France se confondait donc avec la demeure particulière du détenteur de la charge, sans qu'il ne soit fait de différences entre le caractère public et privé de cette dernière. Avec l'installation définitive de la Chancellerie à Paris dans cette grande demeure parisienne, le premier officier de la Couronne disposait enfin d'un hôtel de fonction digne de ce nom. La sédentarisation de l'institution était d'autant plus remarquable que les hôtels " de dignitaires ", exclusivement réservés aux titulaires de charges importantes - secrétaires d'État, chancelier, lieutenant général de Police, etc. - étaient encore rares dans la capitale au début du XvIII ${ }^{\mathrm{e}}$ siècle ${ }^{5}$. Le retour de la Cour à Paris, tout comme le regain d'autorité et de prestige de l'office de chancelier sous la Régence, ont vraisemblablement contribué à fixer définitivement la Chancellerie dans cet hôtel.

4 L'ironie de l'histoire veut que le chef de la Justice royale s'installât dans la demeure d'un richissime financier accusé de malversations et de détournements des fonds royaux. Construit en 1700 par l'architecte Robert de Cotte (1656-1735) pour le financier Joseph Guillaume de La Vieuville, dans le cadre de l'aménagement régalien de la nouvelle place Vendôme [fig. 1], l'hôtel fut acquis en 1706 par François Michel Guyhou de Bruslon qui agissait pour sa tante, Marie Suzanne Guyhou, l'épouse de Paul Poisson de Bourvallais (1658-1719).

Figure 1

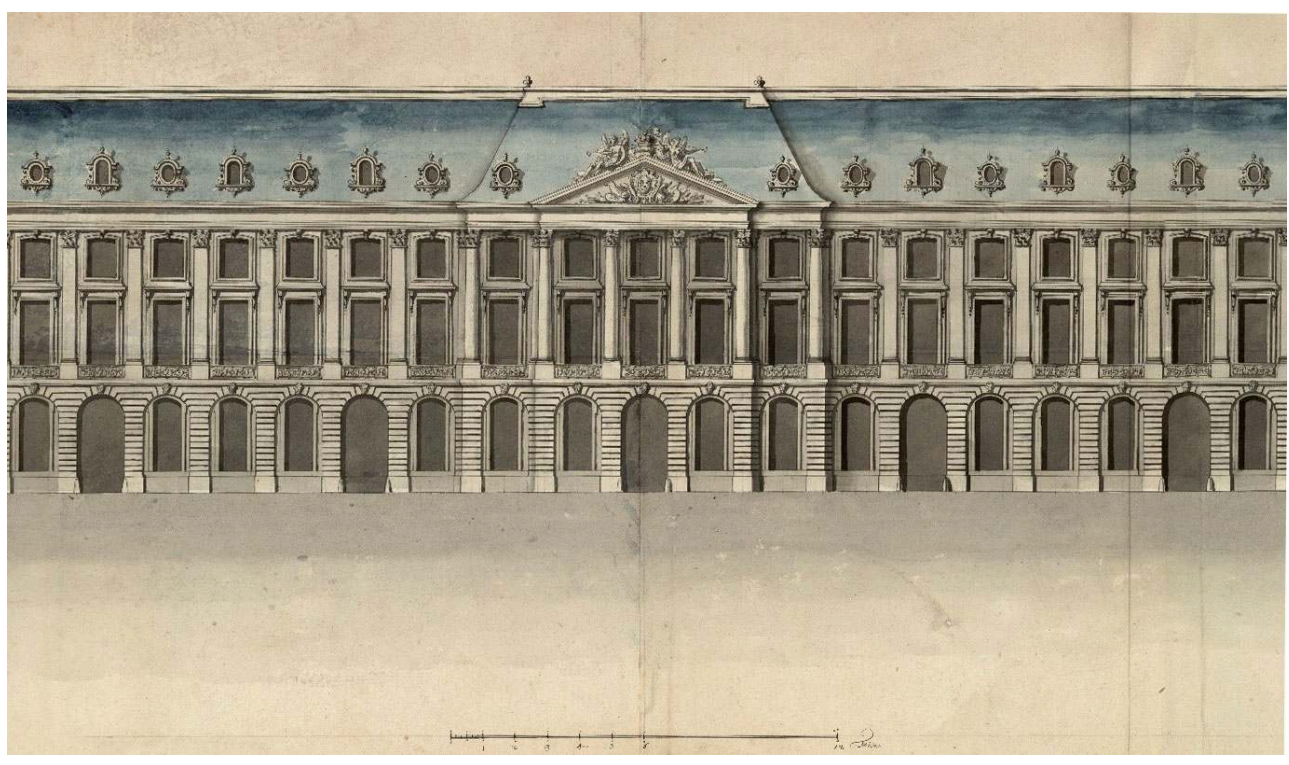

Élévation de la place Louis-le-Grand en perspective (détail), attribué à Robert de Cotte, 1699, dessin conservé à la Bibliothèque nationale de France.

Reproduction BNF, département des Estampes et de la Photographie. 
Ce flamboyant propriétaire, décrit par Saint-Simon comme «l'un des plus riches traitants » du royaume ${ }^{6}$, entreprit aussitôt de redécorer luxueusement sa nouvelle résidence dont les travaux furent confiés à l'architecte Jean-Baptiste Bullet de Chamblain (1665-1726). La richesse et l'ascension fulgurante de Bourvallais se retournèrent cependant vite contre lui et, accusé de concussion des deniers royaux par la Chambre ardente, il fut arrêté et embastillé le 9 mars 1716. À l'issue de plusieurs mois de procès, il dut céder ses biens à l'État et son hôtel de la place Vendôme fut affecté à la Chancellerie [fig. 2].

Figure 2

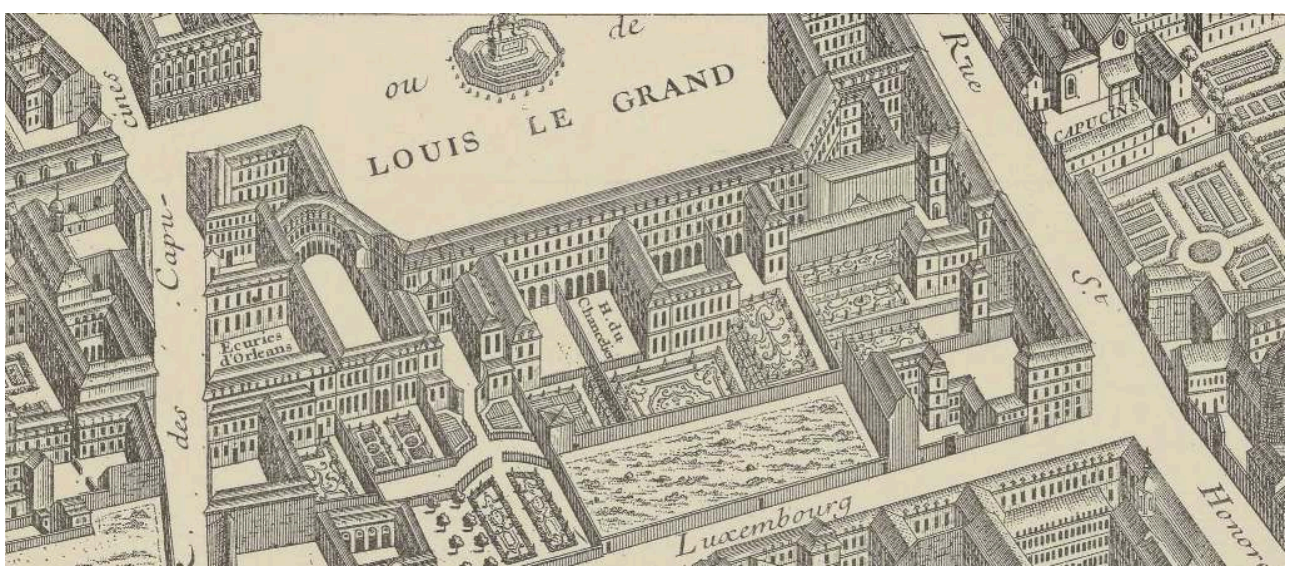

Paris au XVIII e siècle, dit Plan de Turgot (détail de la planche 19), Michel-Étienne Turgot, 1734-1739, gravure conservée à la Bibliothèque nationale de France.

Reproduction BNF, département des Estampes et de la Photographie.

6 Dès lors, l'hôtel fit l'objet d'importants travaux d'aménagement et de décoration afin d'accueillir dignement le chancelier. Un cartouche, sur lequel on pouvait lire « Hôtel du Chancelier de France ", fut placé au-dessus de la porte cochère de l'hôtel pour en indiquer la nouvelle et prestigieuse fonction. Bien que ce premier chantier ne soit que très peu documenté et que les sources d'archives ne permettent pas d'en connaître la chronologie précise, plusieurs plans conservés aux Archives nationales et à la Bibliothèque nationale de France fournissent de précieuses informations quant aux transformations majeures entreprises dans la demeure sous la Régence. Ces dernières consistèrent, dans un premier temps, à réunir l'hôtel de Bourvallais à l'hôtel voisin du $\mathrm{n}^{\circ} 11$ de la place Vendôme, alors connu sous le nom d'hôtel de Simiane ${ }^{7}$. Au rez-dechaussée, les espaces réservés au service des écuries et des remises furent déplacés dans le corps de bâtiment sur la place, permettant ainsi de libérer le rez-de-chaussée du logis sur le jardin et d'y disposer un grand appartement d'apparat [fig. 3 et 4]. À l'étage, le chancelier, "qui [craignait] le bruit des carrosses et qui [avait] beaucoup à travailler », fit aménager un appartement de commodité ayant vue sur les parterres ${ }^{8}$. 
Figure 3

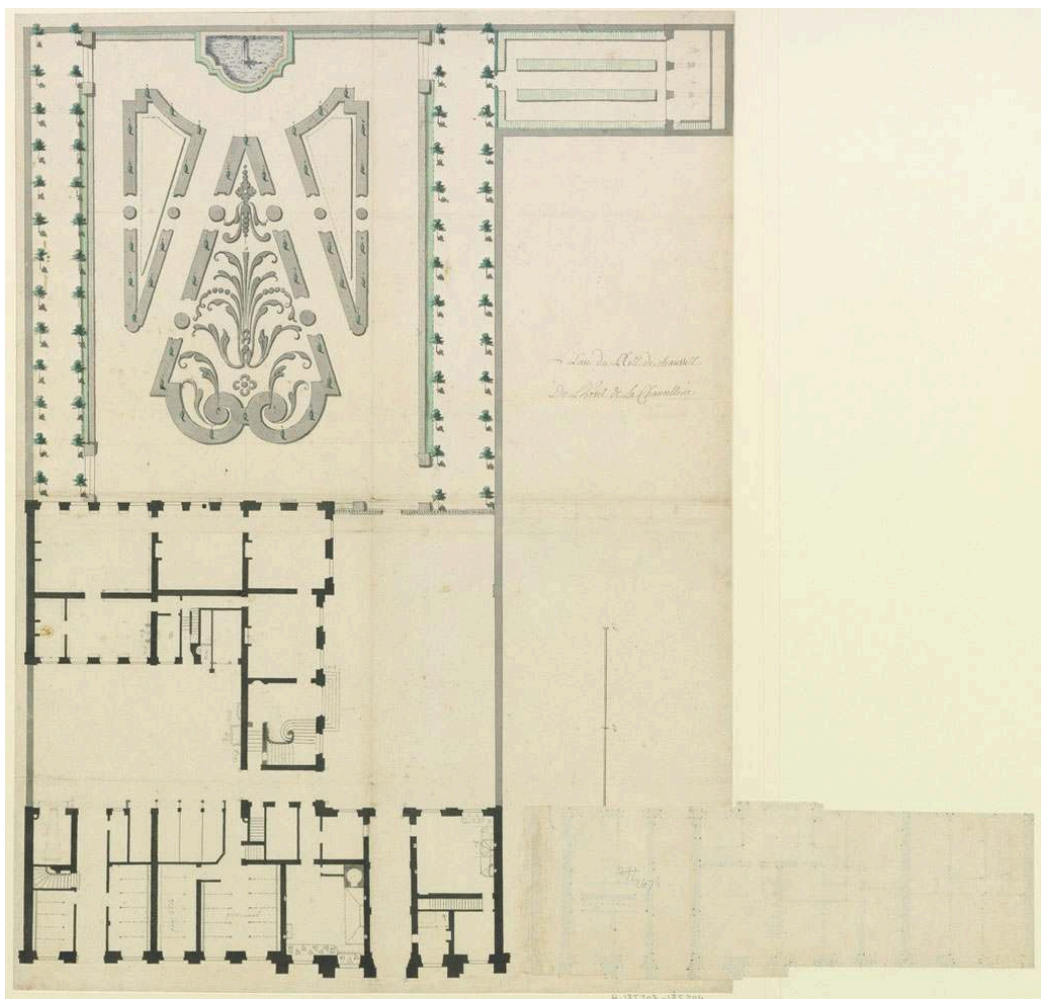

Plan du rez-de-chaussée de I'hôtel de la Chancellerie de France, auteur inconnu, 1718, dessin conservé à la Bibliothèque nationale de France.

Reproduction BNF, département des Estampes et de la Photographie, https://gallica.bnf.fr/ark:/12148/ btv1b69373301/f2. item.r=rez\%20de\%20chauss\%C3\%A9e\%20chancellerie [lien valide en novembre 2021]. 


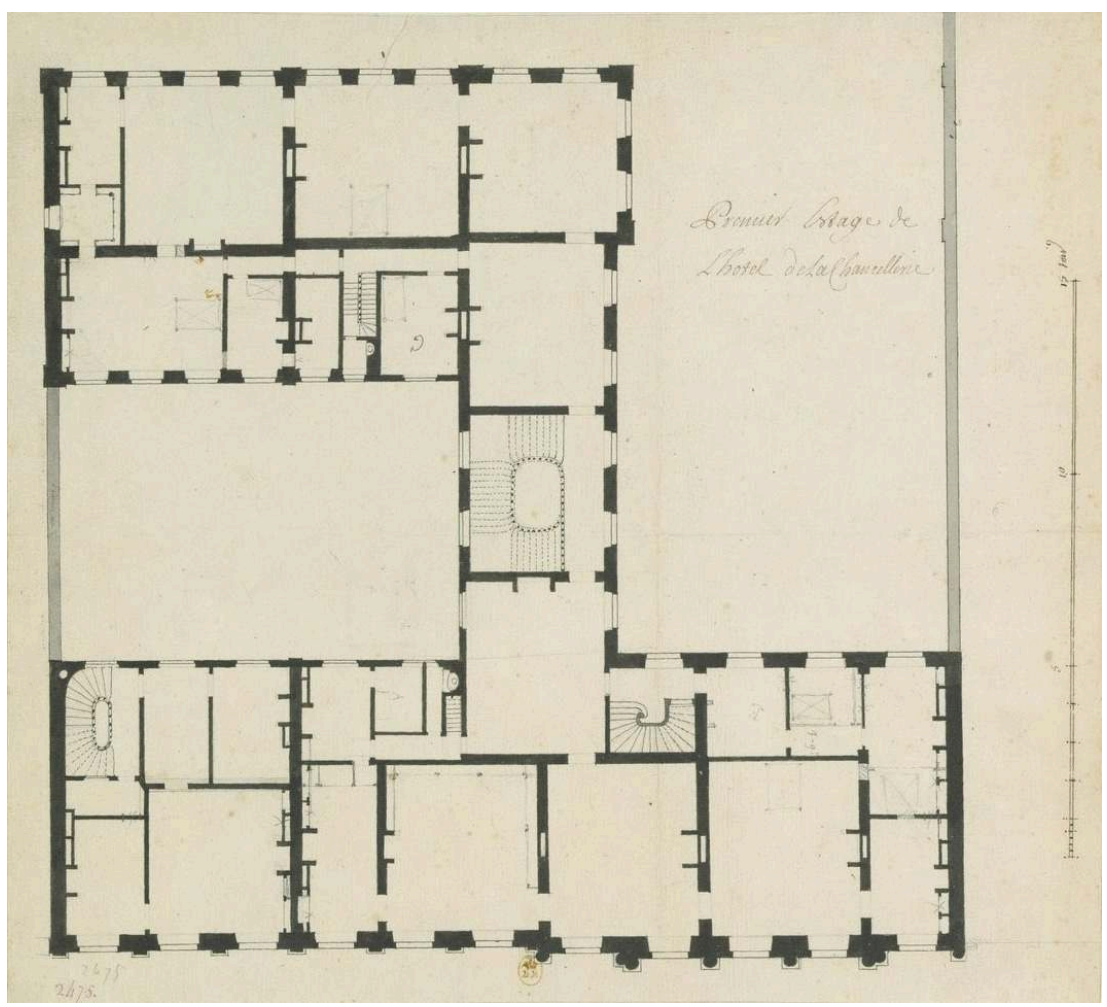

Plan du premier étage de l'hôtel de Chancellerie, auteur inconnu, 1718, dessin conservé à la Bibliothèque nationale de France.

Reproduction BNF, département des Estampes et de la Photographie, https://gallica.bnf.fr/ark:/12148/ btv1b55001367s/f7.item.r=plan\%20h\%C3\%B4tel\%20chancellerie [lien valide en novembre 2021].

7 Commencés dès 1717 , ces travaux d'appropriation étaient probablement achevés en 1719: une fois agrandi et correctement aménagé, l'hôtel était prêt à accueillir le chancelier d'Aguesseau, qui s'y installa au printemps $1720^{\circ}$.

8 Il fallut attendre la Révolution pour que le chancelier et tous ses services s'établissent définitivement dans l'hôtel parisien, après avoir été contraints de quitter Versailles, à l'instar du roi et des autres membres du gouvernement. Quelques mois plus tard, en décembre 1790, l'office de chancelier de France fut supprimé, au profit du portefeuille de ministre de la Justice. Étonnamment pourtant, la situation politique particulièrement conflictuelle de la fin du xvIII siècle n'eut aucune incidence sur l'occupation, par le nouveau représentant de la Justice nationale, de l'hôtel de la place Vendôme - rebaptisée pendant un temps "place des Piques»; et les révolutions, les coups d'État et les bouleversements majeurs qui se succédèrent au cours du XIX ${ }^{e}$ siècle n'eurent d'ailleurs pas plus de conséquences. Du Directoire au xxe siècle, en passant par la Restauration et le Second Empire, le ministère de la Justice, faisant face aux tempêtes sociales et politiques, resta solidement amarré à l'ancien hôtel de la Chancellerie.

9 Si le ministère ne devait plus jamais quitter les lieux historiques de la place Vendôme, d'inévitables travaux d'" appropriations ${ }^{10}$ » y furent conduits au gré des changements de régime et de goût : les projets d'aménagement de l'architecte Pierre-Nicolas Bénard (1752-1817) pour le duc de Massa sous le Premier Empire ${ }^{11}$ précédèrent la construction d'une immense salle à manger d'apparat sous la Restauration, par l'architecte FrançoisHippolyte Destailleur (1787-1852), à la demande du ministre Pierre-Denis 
de Peyronnet; suivirent ensuite les grandes campagnes de décoration du Second Empire. Toutefois, hormis la construction de ladite salle à manger - aujourd'hui appelée « galerie Peyronnet »- le gros œuvre de l'hôtel de Bourvallais n'a pas subi de transformations majeures depuis le début du XviII siècle. Il est vrai que l'ancien hôtel aristocratique était tout à fait adapté à recevoir les appartements de réception et d'habitation d'un ministre; mais inversement, la place pour accueillir les bureaux, toujours plus nombreux, fit rapidement défaut dans cet édifice qui n'avait pas été conçu, à l'origine, pour recevoir autant de services administratifs. Afin de pallier ce problème, deux immeubles de bureaux furent construits sur la parcelle, en bordure de la rue Cambon (ancienne rue Neuve-du-Luxembourg). Le premier, construit à partir de 1826 sous le ministère de Peyronnet, existe toujours ${ }^{12}$. Si l'aspect extérieur de cet édifice administratif est encore bien conservé, le bas-relief et le fronton qui ornent la porte d'entrée datent des années $1950^{13}$. Quant à la seconde extension, elle fut construite dans les années 1940-1950, en bordure de la rue Cambon ${ }^{14}$.

\section{Les décors intérieurs : $\mathrm{XVIII}{ }^{\mathrm{e}}$ et $\mathrm{XIX}{ }^{\mathrm{e}}$ siècles}

10 À l'inverse du bâtiment lui-même, l'ensemble des décors intérieurs de l'hôtel de la Chancellerie a été considérablement transformé au fil des années. Si certaines boiseries, encore visibles aujourd'hui, datent vraisemblablement de l'époque de la Régence, les mentions de ces travaux citées dans les comptes des Bâtiments du roi sont trop vagues pour établir un rapprochement direct avec les décors conservés in situ. Nous savons néanmoins qu'ils ont été exécutés au cours de l'année 1718, sous la direction de Robert de Cotte, et réalisés - au moins pour une grande partie - par les sculpteurs employés sur le chantier de Versailles, notamment René Charpentier, Jean Voiriot et Jules Degoullons. C'est en effet à cette équipe que fut effectué en 1721 le paiement le plus important pour le décor de la demeure ${ }^{15}$. Deux dessins peuvent être rapprochés de ces aménagements. Le premier, portant la mention manuscrite "Corniche pour le grand cabinet de Monseigneur le chancellier», est conservé au Nationalmuseum de Stockholm ${ }^{16}$; le second est une "Élévation de la chambre du Chancellier ", conservée à la Bibliothèque nationale de France ${ }^{17}$.

11 De cette première campagne de décoration date très certainement le décor du salon dit "des Portraits », situé dans l'enfilade du premier étage sur le jardin, et qui était, sous l'Ancien Régime, le grand cabinet de l'appartement du chancelier [fig. 5]. 
Figure 5

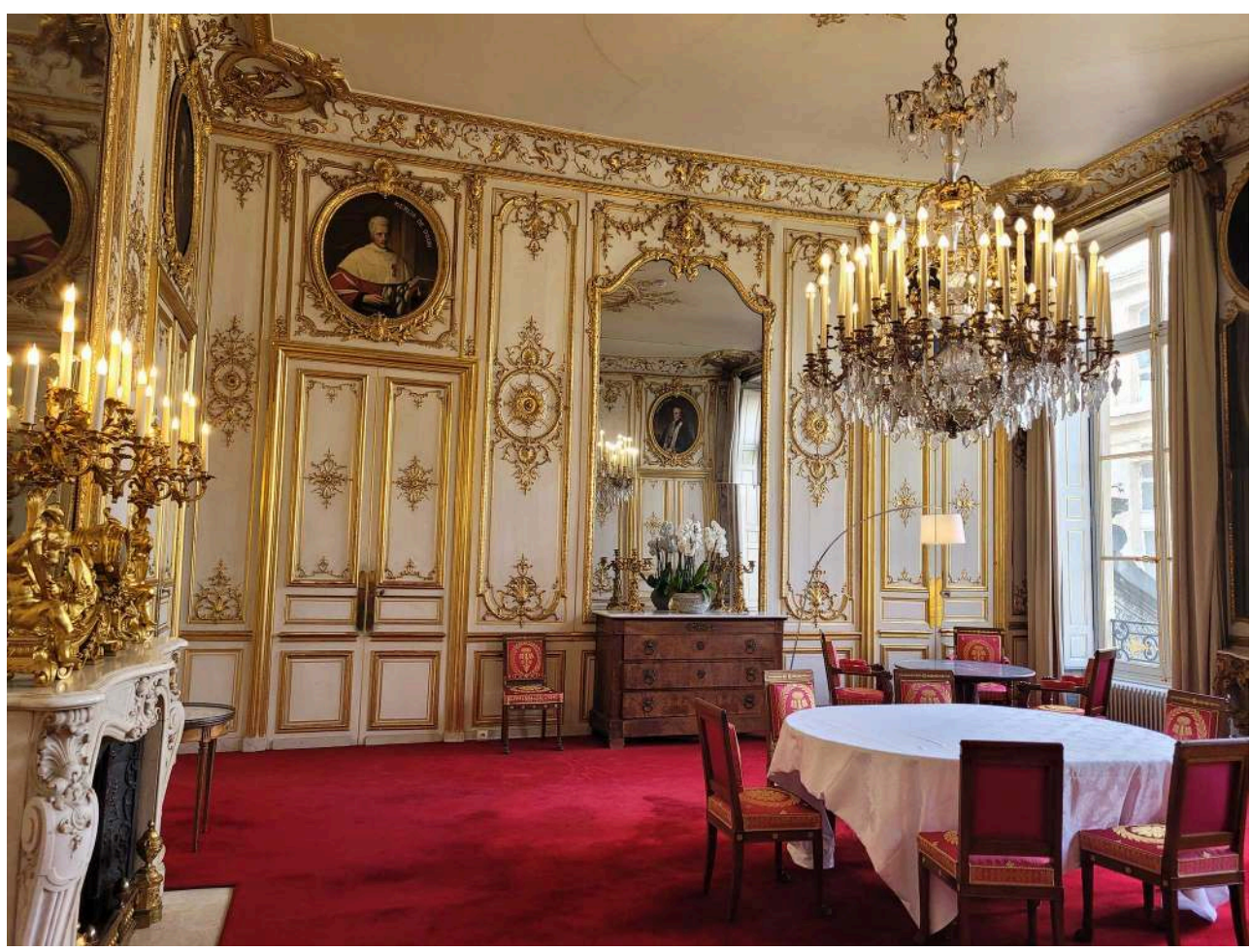

Salon des Portraits (ancien salon doré), 2021.

(c) Clémence Pau.

12 L'ensemble de ses boiseries, corniches et rosace pourrait même être attribué à l'atelier de Degoullons, d'après un dessin de Robert de Cotte ${ }^{18}$. Appelée dans les sources « sallon doré ", cette pièce présente en effet un décor caractéristique du style des Bâtiments du roi, avec de grandes roses placées au milieu des panneaux et de vastes trumeaux de glace. Les entrelacs de la rosace du plafond sont habités par plusieurs petits dragons et la corniche à gorge est peuplée de putti et d'oiseaux. Les médaillons placés dans les quatre angles du même plafond devaient quant à eux évoquer la nouvelle destination de l'hôtel: dans un cartouche ailé, prend place une allégorie de la Justice armée du glaive et de la balance à laquelle répond, dans un autre angle, la Force solidement appuyée sur le fût d'une colonne ${ }^{19}$ [fig. 6]. 
Figure 6

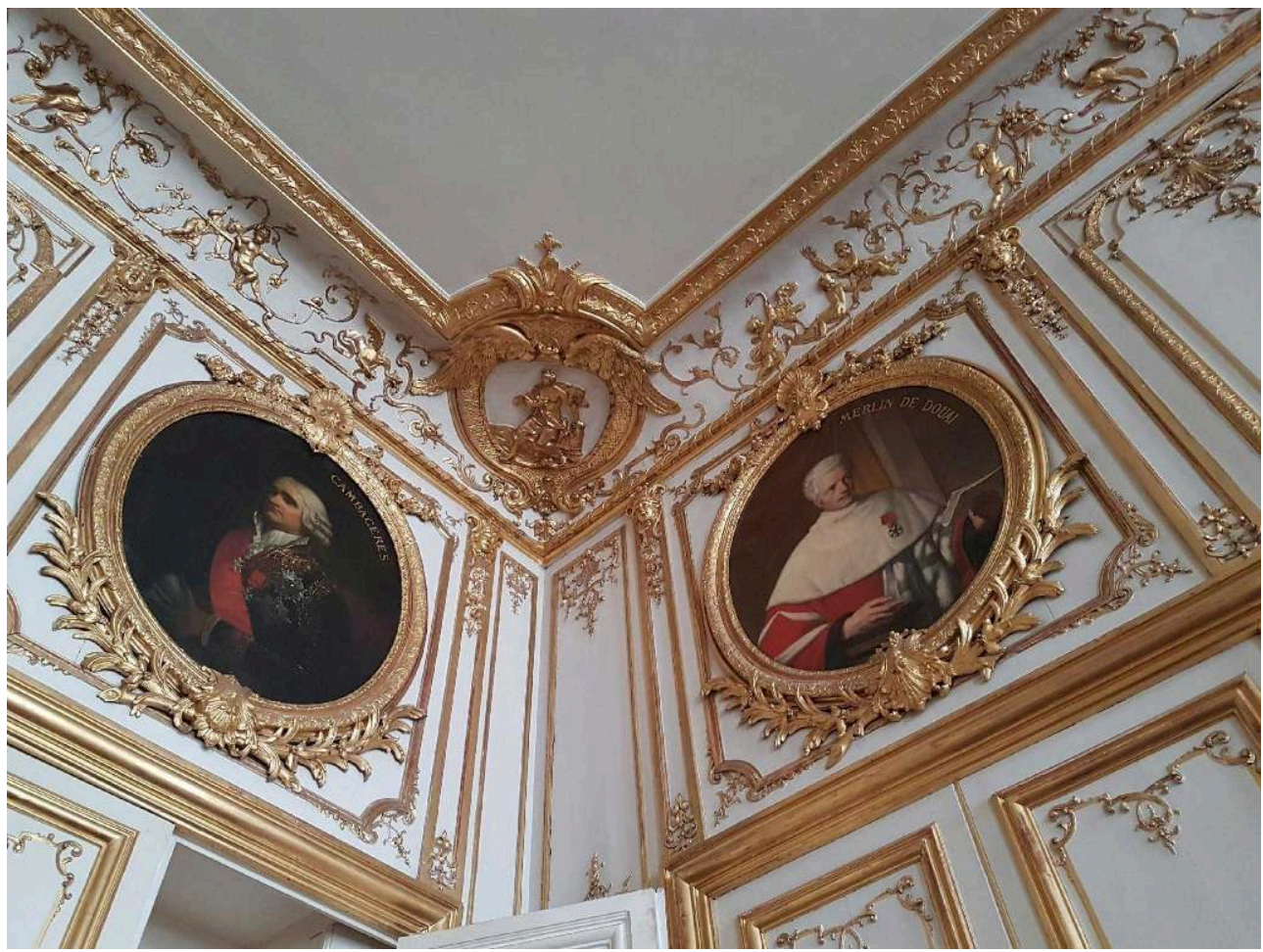

Détail de la corniche du salon des Portraits, 2018.

(c) Clémence Pau.

Enfin, les six dessus-de-porte de forme ovale, qui ont donné le nom actuel de «salon des Portraits » à cette pièce, ont été réalisés en 1846 par les peintres Abel de Pujol (1785-1861) et Louis Henri de Rudder (1807-1881) et renferment les portraits de chanceliers et de gardes des Sceaux de l'Empire ${ }^{20}$. De même, la cheminée actuelle encadrée par deux élégants pilastres d'ordre composite qui semblent, quant à eux, d'origine - $\mathrm{y}$ a été placée au XIX ${ }^{\mathrm{e}}$ siècle ${ }^{21}$.

D'autres décors pourraient également être datés des années 1717-1718 mais ils ont été, de toute évidence, embellis et modifiés au cours du XIX siècle. C'est le cas des boiseries de l'actuel bureau du ministre, situé au rez-de-chaussée, sur le jardin [fig. 7]. Plusieurs éléments, comme la corniche et certains ornements des panneaux, semblent être d'origine $^{22}$. 
Figure 7

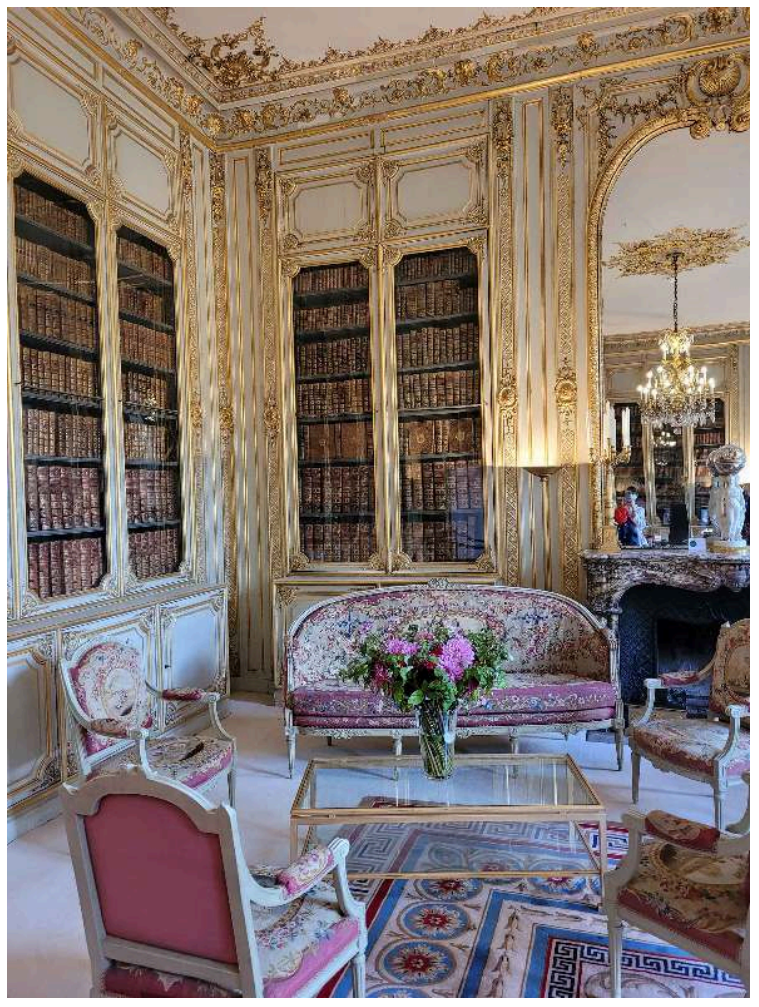

Bureau du ministre de la Justice, 2021.

(C) Clémence Pau.

Toutefois, une partie des lambris qui font corps avec les bibliothèques vitrées fut probablement remaniée sous la monarchie de Juillet, lorsque l'on chargea l'entrepreneur Petit de réaliser de nouvelles bibliothèques dans le cabinet du ministre en 1840-1841 ${ }^{23}$. La même question se pose à propos de la salle du Sceau, où le décor du $\mathrm{xvIII}^{\mathrm{e}}$ de l'ancienne salle d'audience du chancelier paraît là aussi avoir été fortement remanié. Ainsi, la corniche pourrait être d'origine mais il est aussi possible qu'elle ait été réalisée à partir d'un moulage, suivant une pratique très courante au XIX ${ }^{e}$ siècle. En effet, son modèle est très proche - pour ne pas dire identique - à celui du salon des Portraits, au premier étage. Les portraits de Michel de L'Hospital (1505-1537), de Mathieu Molé (1584-1656) et de Henri-François d'Aguesseau (1668-1751), grandes figures de la Chancellerie sous l'Ancien Régime, sont venus compléter le décor au XIX ${ }^{\mathrm{e}}$ siècle.

Le reste des décors de l'hôtel du ministère date du xix siècle et même, pour l'essentiel, du Second Empire. Ils ont été conçus par Hippolyte Destailleur (1822-1893) qui avait succédé à son père, François-Hippolyte Destailleur (1787-1852), comme architecte du ministère de la Justice en 1852. L'année suivante, le fils se vit confier la restauration de la salle à manger et des anciens salons de réception de l'ancien hôtel de Bourvallais, ainsi que le renouvellement de la distribution de ses appartements ${ }^{24}$. D'après son biographe, Georges Duplessis, Hippolyte Destailleur fit ici «œuvre d'architecte mais aussi d'érudit ». Respectueux des décors anciens et soucieux de conserver l'intégrité architecturale de l'édifice, le jeune architecte réussit en effet à « subordonn[er] le style de la décoration à l'époque où le monument qui devait contenir ces décorations avait été construit ${ }^{25} »$. 
Ainsi, le salon des Oiseaux est représentatif de cette campagne, avec ses riches boiseries, peintes en blanc et or, caractéristiques du « style du Second Empire » [fig. 8].

Figure 8

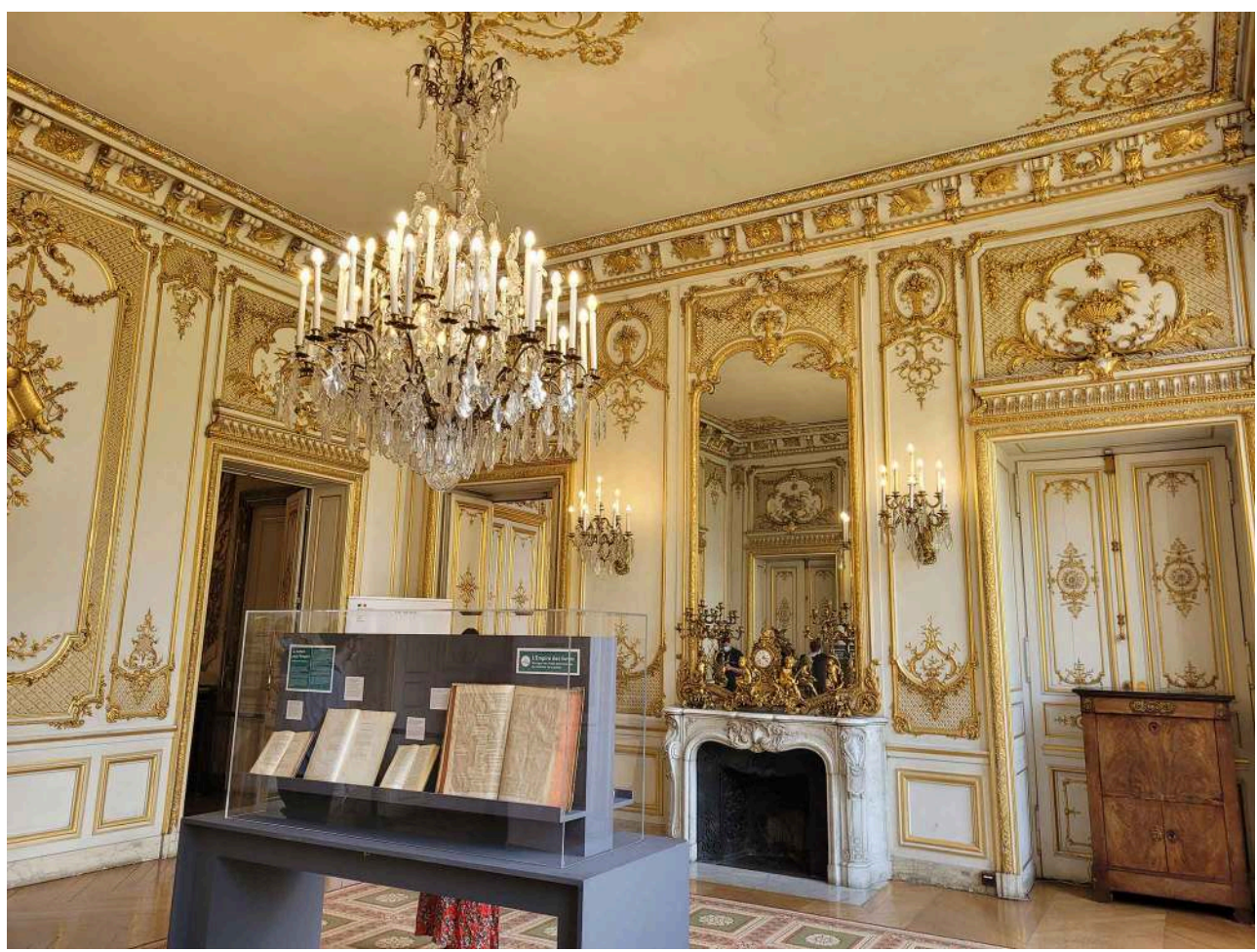

Salon des Oiseaux, 2021.

(C) Clémence Pau.

Des guirlandes de fleurs et des corbeilles de fruits peuplées d'oiseaux ornent les dessusde-porte, et la corniche est enrichie de petites consoles alternant avec des motifs symboliques. L'un d'eux représente le bouclier des Amazones, également appelé " pelte ", symbole de protection. Le grand panneau faisant face à la place Vendôme est orné d'une composition dans le style du XviII ${ }^{\mathrm{e}}$ siècle regroupant tous les symboles de la Justice: les Tables de la Loi, le glaive, la main de Justice, la balance, les feuilles de chêne, le faisceau des licteurs et le flambeau.

Le décor du petit salon, au rez-de-chaussée sur le jardin, date également du Second Empire [fig. 9]. Exécutées dans un style rocaille très chargé, les boiseries de bois foncé présentent là encore plusieurs attributs de la Justice: Code civil, feuilles de chêne, glaive et flambeau. Le grand trumeau de glace, posé sur la cheminée, est quant à lui orné d'un putto tenant dans ses mains une balance et une épée, accompagné de deux petits dragons. Les deux peintures en grisaille qui occupent les dessus-de-porte représentent la Sagesse et la Force en buste. Le symbole de la balance se retrouve enfin sur la corniche, tandis que dans les angles sont placés les « $\mathrm{N}$ » surmontés de la couronne impériale, entourés de feuilles de laurier et de chêne, en référence à l'empereur Napoléon III. Ce même motif orne la rosace du plafond. 
Figure 9

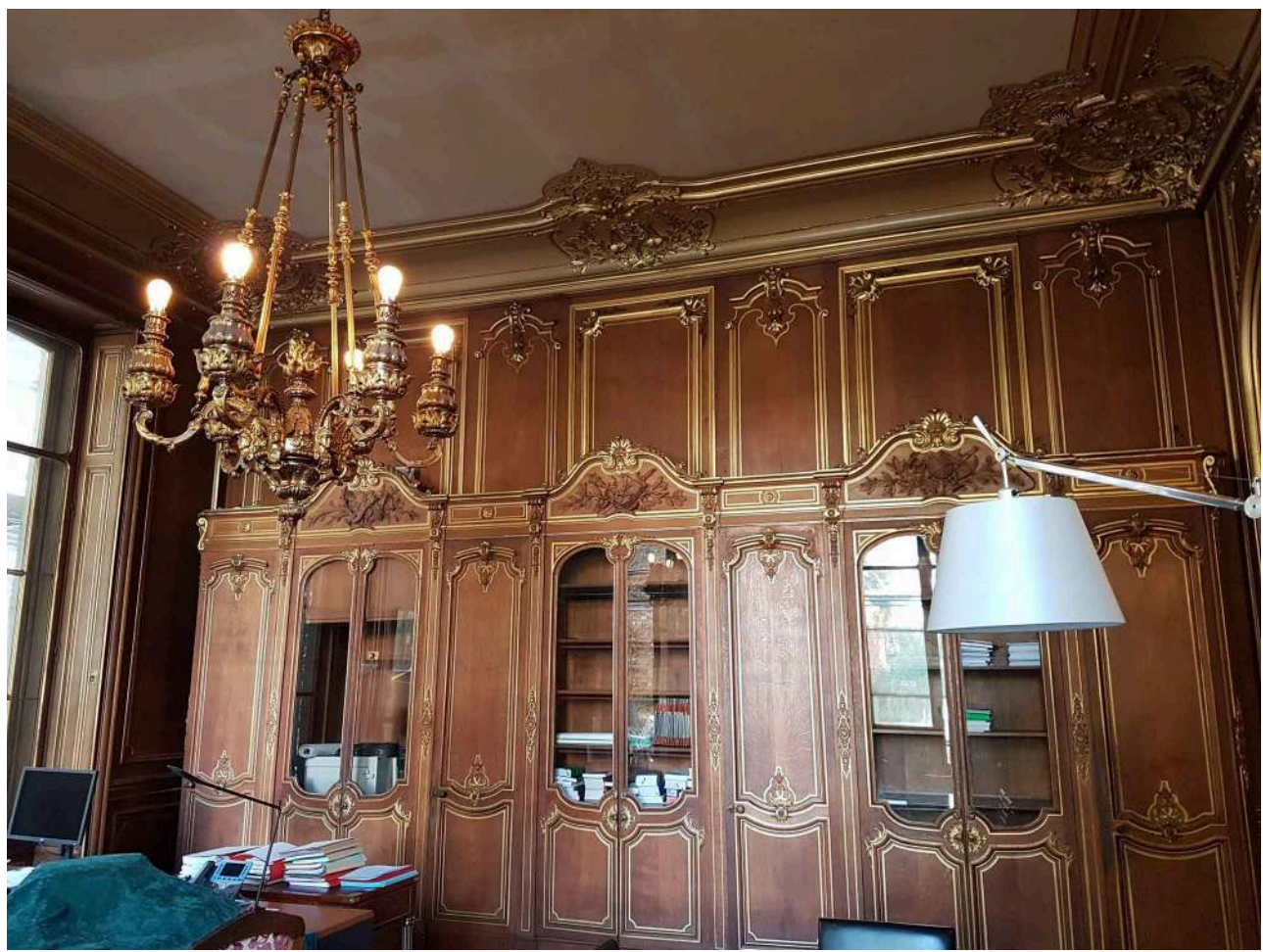

Petit salon, 2017

(c) Clémence Pau.

C'est encore à Hippolyte Destailleur que l'on doit l'actuel décor de l'ancienne salle à manger d'apparat de l'hôtel, dite « galerie Peyronnet » [fig. 10]. 
Figure 10

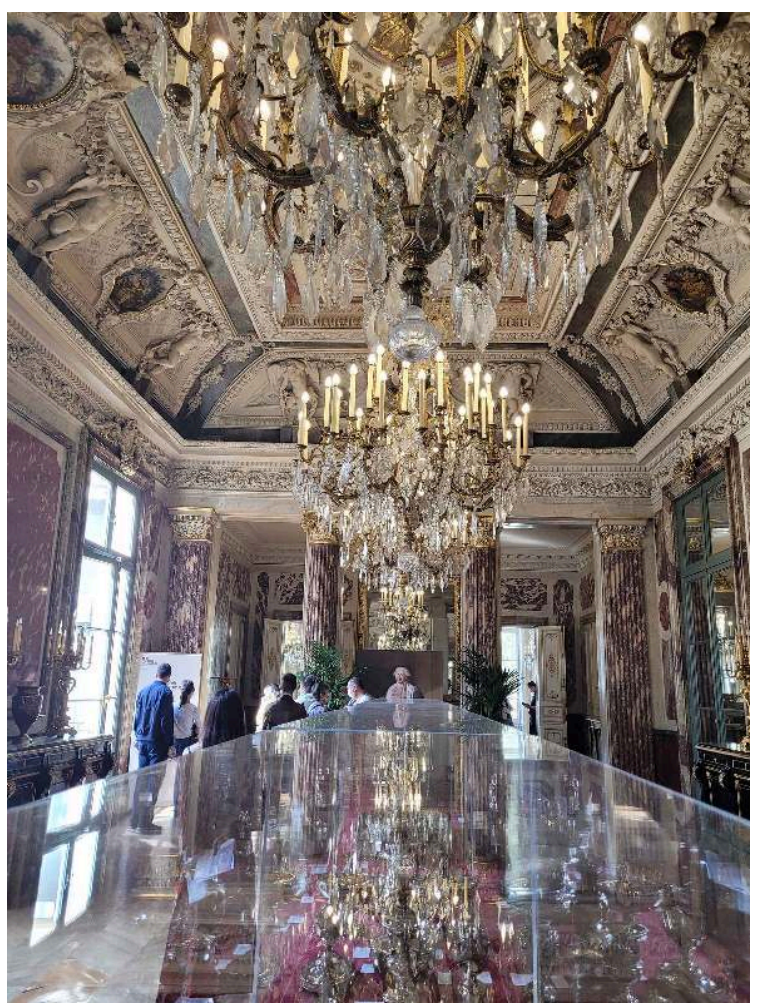

Salle à manger d'apparat dite « Galerie Peyronnet », 2021.

(C) Clémence Pau.

21 Aucune source d'archives ne permet malheureusement d'établir précisément le déroulement du chantier de cette grande salle, construite entre 1826 et 1827 sous le ministère de Peyronnet, et dont le décor originel est parfaitement inconnu. Une rare mention contemporaine à sa réalisation la décrit succinctement comme une «pièce assez vaste, mais simple et peu décorée ${ }^{26} »$. Aussi, le décor visible aujourd'hui date sans aucun doute possible des années 1850 et doit être rendu à Destailleur fils ${ }^{27}$. Particulièrement somptueux, il est en effet beaucoup plus proche des goûts du Second Empire que de ceux de la Restauration: les murs sont revêtus de marbres polychromes et les colonnes composites, réalisées en carton-pierre, sont peintes en faux marbre. Le plafond à voussures est richement orné de marbres, de cartouches, de putti et de guirlandes de fleurs, le tout réalisé en stuc ou en trompe-l'œil. Enfin, on retrouve au-dessus de chaque baie un médaillon dans lequel a été sculpté le « $\mathrm{N}$ » de Napoléon III, surmonté d'une couronne impériale.

\section{Un patrimoine classé au titre des monuments historiques}

22 L'hôtel du ministère de la Justice offre une particularité qui le distingue des autres hôtels ministériels : son adresse est prestigieuse, et même royale! La place Vendôme est en effet un lieu emblématique de la capitale et les élévations dessinées par Jules Hardouin-Mansart en 1699 firent très rapidement l'objet d'un classement au titre des monuments historiques. Dès 1862, la façade antérieure de l'hôtel de Bourvallais était 
ainsi classée, tout comme celles de ses voisins, sous l'appellation «façade de la place Vendôme ${ }^{28} »$. Aussi étonnant que cela puisse paraître, cette décision de protection fut négligée, voire totalement oubliée, la place subissant même un certain nombre de dégradations au fil des années. Il fallut attendre l'extrême fin du xIX siècle pour que se manifeste enfin un réel intérêt pour l'imposant espace urbain voulu par Louis XIV et, de manière plus générale, pour l'architecture du XVIII ${ }^{e}$ siècle $^{29}$. En effet, comme l'a observé Ruth Fiori, la patrimonialisation de l'architecture française moderne de l'Ancien Régime à Paris ne s'est opérée qu'au tournant du XIX ${ }^{\mathrm{e}}$ siècle ${ }^{30}$.

Les associations de sauvegarde et les autorités de la Ville de Paris commencèrent dès lors à se préoccuper sérieusement de la préservation de l'esthétique de la place Vendôme ${ }^{31}$. En 1895, les Amis des Monuments parisiens - association créée en 1884 par l'architecte Charles Normand (1858-1934) - sollicitèrent l'administration pour remédier à l'envahissement de celle-ci par les écriteaux et les enseignes sur calicot ${ }^{32}$ qui avaient fini par causer la disparition de certains mascarons ${ }^{33}$. Quelques années plus tard, le préfet de la Seine souhaita à son tour, à l'instar de la Commission du Vieux Paris, rendre à la place son « harmonie primitive ». Pour cela, il fut demandé au ministre de la Justice de supprimer les persiennes en bois de ses fenêtres "qui [nuisaient] à l'esthétique de la place Vendôme, [masquaient] l'architecture et, par leur aspect, [détruisaient] l'uniformité des édifices en bordure ${ }^{34} »$. Évidemment, la résidence ministérielle n'était pas la seule dans ce cas et son association avec les autres façades de la place offrait une vision architecturale très disparate ${ }^{35}$, mêlant stores, persiennes en bois et enseignes commerciales, d'ailleurs toujours en place ${ }^{36}$ [fig. 11].

Figure 11

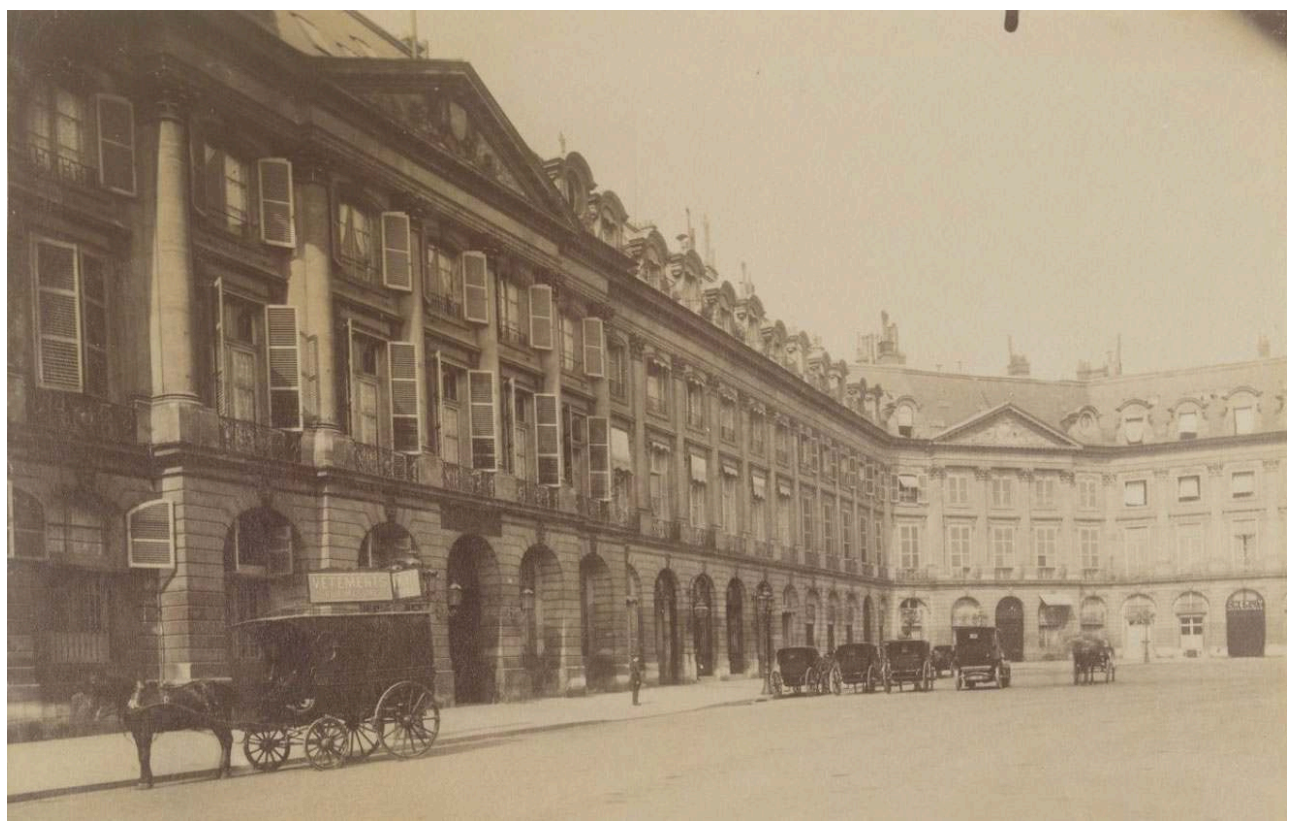

Place Vendôme, Eugène Atget, 1906, photographie sur papier albuminé conservée à la Bibliothèque nationale de France.

Reproduction BNF, département des Estampes et de la Photographie, https://gallica.bnf.fr/ark:/12148/ btv1b10516352h/f1.item.r=Eug\%C3\%A8ne\%20Atget,\%20Place\%20Vend\%C3\%B4me.zoom\# [lien valide en novembre 2021]

Par la suite, la Première Guerre mondiale n'épargna pas l'hôtel du garde des sceaux, qui fut fortement endommagé par des bombardements aériens dans la nuit du 27 au 28 juin 
1918. Une partie de la charpente et un mur de refend furent détruits, la couverture détériorée sur toute sa surface et l'ensemble des vitres des façades donnant sur la place Vendôme, sur le jardin et sur la cour d'honneur brisées. Les réparations, estimées à 349230 francs $^{37}$, tardèrent à être réalisées et au début de l'année 1919, le ministre se plaignait encore du plafond de la grande salle à manger qui n'avait toujours pas été réparé38. De même, il fallut remettre en état le jardin de l'hôtel dont la terre avait été prélevée pour protéger le pied de la colonne Vendôme ${ }^{39}$.

C'est dans ce contexte particulier que furent menées les premières démarches visant à préserver et conserver les décors les plus anciens de l'hôtel de Bourvallais. Au sortir de la guerre, une demande de classement au titre des monuments historiques fut déposée pour les lambris et corniches du salon des Portraits, finalement inscrits sur l'Inventaire supplémentaire par un arrêt du 29 décembre $1925^{40}$, arrêté reconduit deux ans plus tard, le 2 mai $1927^{41}$. Au même moment, on se préoccupa de l'état des façades de la place Vendôme. Le classement de 1862 ayant été oublié, des recherches furent effectuées pour savoir si ces dernières faisaient, ou non, l'objet d'une protection. Le 23 mai 1923, le ministre de l'Instruction publique et des Beaux-Arts certifiait au ministre que «la façade du ministère de la Justice, place Vendôme à Paris, [figurait] page $52,1^{\text {re }}$ colonne, $31^{\text {e }}$ alinéa, sur la liste générale des monuments classés, publiée officiellement en 1900 à l'Imprimerie nationale ${ }^{42}$ ». Et de fait, le classement apparaissait déjà dans les listes de $1862^{43}, 1875^{44}, 1887^{45}$ sous la désignation de « façades de la place Vendôme » ou « façades des maisons de la place Vendôme ».

Il fallut attendre les années 1950 pour que l'intérêt patrimonial se porte, non plus seulement sur les parties " anciennes» de l'hôtel mais aussi sur les nombreux décors datant du XIX ${ }^{e}$ siècle. Il est toutefois important de noter que l'attention nouvelle portée aux décors du Second Empire fut, dans un premier temps, bien plus historique que réellement artistique. En effet, on déplorait en 1952 que les panneaux de « reconstitution » des riches boiseries blanc et or aient été réalisés en plâtre et non en bois, que les sculptures n'aient été que de stuc et les moulures du carton-pierre doré à l'huile. Si la qualité n'était plus la même, jugeait-on alors, l'effet obtenu se montrait toutefois convaincant ${ }^{46}$ : ce décor "encore à peu près intact " méritait donc d'être protégé « comme type de l'effort de cette époque pour compléter dans l'esprit un décor ancien ${ }^{47}$ ». Par ailleurs, la demande du ministère devait également faire face à la "disparition rapide des derniers témoins du goût du Second Empire pour le grand décor traditionne ${ }^{48}$ ", le xIX $^{\mathrm{e}}$ siècle souffrant en effet d'un désintérêt de la part du monde artistique et intellectuel d'alors, désintérêt très préjudiciable pour sa sauvegarde. Les ensembles décoratifs de l'hôtel de Bourvallais concernés par cette requête étaient, au rez-de-chaussée sur le jardin, le salon d'angle, pour son «bon exemple des boiseries bois verni et or du temps ", la salle du Sceau avec ses «boiseries blanc et or Second Empire dans le goût Louis XV » et la bibliothèque. À l'étage, étaient concernés le décor du salon d'angle - avec son parquet d'origine à compartiments et son décor du xix siècle -, le salon des Oiseaux et le salon des Portraits " décoré d'une boiserie du début du XVIII ${ }^{e}$ siècle assez remaniée et redorée ${ }^{49}$ ». Enfin, il fallait encore ajouter à cette liste la salle à manger d'apparat et le salon rouge sur la place Vendôme. Si la demande de protection, relativement précoce pour des décors xix siècle, ne fut pas suivie d'effet immédiat, elle témoigne bien, et plus largement, de la lente reconnaissance de l'architecture du XIX $x^{e}$ siècle en tant que patrimoine - au même titre que l'architecture antique, médiévale et moderne ${ }^{50}$. Enfin, si les décors du XIX $x^{e}$ siècle 
tardèrent à être reconnus comme étant véritablement dignes d'intérêt par l'administration, les dernières parties «anciennes » de l'hôtel de Bourvallais qui ne faisaient pas encore l'objet d'une protection - à savoir, l'escalier d'honneur du $\mathrm{XVIII}^{\mathrm{e}}$ siècle, les façades et les toitures sur jardin - furent inscrites à l'Inventaire supplémentaire des monuments historiques, par arrêté du 4 novembre $1952^{51}$.

Les choses n'évoluèrent guère plus jusqu'en 1977. À cette date, et suite aux avis favorables de l'architecte en chef des monuments historiques, du conservateur régional des Bâtiments de France et de l'inspecteur général des monuments historiques ${ }^{52}$, la Commission supérieure s'exprima en faveur du classement des façades sur le jardin de l'ensemble de l'hôtel de Bourvallais, malgré quelques transformations «peu heureuses » sur certaines toitures, notamment une double rangée de lucarnes percées dans les combles donnant sur la grande cour ${ }^{53}$. Les élévations furent finalement inscrites à l'Inventaire supplémentaire par l'arrêté du 22 février 1980 ; le même jour, un autre arrêté classait enfin au titre des monuments historiques ${ }^{54}$ la façade et la toiture sur la place Vendôme ainsi que plusieurs salons et leur décor ${ }^{55}$. À son tour, le mobilier de l'hôtel fit bientôt l'objet de toutes les considérations, notamment un important ensemble mobilier, propriété du ministère, datant des années 1810-1820 et estampillé Pierre-Antoine ou Louis-Alexandre Bellangé, qui fut lui aussi classé au titre des monuments historiques en $1988^{56}$.

Enfin, l'arrêté du 7 novembre 1991 entérina l'inscription en totalité, sur l'Inventaire supplémentaire des monuments historiques, des bâtiments et des sols du ministère de la Justice, $\mathrm{n}^{\mathrm{os}} 11$ et 13 , place Vendôme - à l'exclusion toutefois des bâtiments de la rue Cambon. Signe de l'évolution du regard sur le patrimoine, ce classement fut décidé en considération de «la qualité architecturale de l'édifice affecté au ministère de la Justice, [de] son importance dans l'ordonnance de la place Vendôme ainsi que [par] l'intérêt de ses décors intérieurs du XVIII ${ }^{\mathrm{e}}$ et du XIX ${ }^{\mathrm{e}}$ siècles ${ }^{57}$ ".

29 Au terme de cette étude, l'ancien hôtel de Bourvallais s'impose comme le siège emblématique de la Justice, tant pour son architecture et ses décors que pour son histoire : il est l'unique bâtiment de la capitale à avoir été, depuis maintenant trois cents ans, le siège continu d'un ministère et de ses ancêtres. Pour autant, si l'hôtel du ministère de la Justice est aujourd'hui reconnu pour sa valeur patrimoniale, nous avons $\mathrm{vu}$ combien cette reconnaissance fut relativement lente et progressive. Comme beaucoup d'autres hôtels aristocratiques, la demeure du garde des sceaux a connu d'importantes transformations au $\mathrm{XIX}^{\mathrm{e}}$ siècle, transformations dont la valeur artistique a été pendant longtemps sous-estimée et dépréciée. Il est aujourd'hui temps de reconsidérer l'édifice dans son entièreté car son architecture et ses décors contribuent, chaque jour un peu plus, au prestige de l'Institution. Et de fait, fort de ce double héritage historique et patrimonial, l'hôtel de Bourvallais apparaît bien comme le précieux témoin de l'histoire de la Justice en France depuis l'Ancien Régime. 


\section{NOTES}

1. Cet article repose en grande partie sur l'ouvrage publié en collaboration avec le ministère de la Justice à l'occasion de la célébration des trois cents ans de l'installation de la Chancellerie de France dans l'hôtel de Bourvallais. Voir: PAU Clémence, L'Hôtel de Bourvallais. 300 ans de Justice place Vendôme, Paris, ministère de la Justice, 2019.

2. Dictionnaire de l'Académie française, Paris, Imprimerie Firmin Didot frères, $1835,6^{\mathrm{e}}$ édition, t. 2 , p. 209, disponible en ligne https://gallica.bnf.fr/ark:/12148/bpt6k50408v/f2.item [lien valide en septembre 2021].

3. PONS Bruno, «L'Hôtel de la Chancellerie », Monuments historiques, $n^{\circ} 172$, janvier-février 1991, p. 104.

4. La situation était différente à Saint-Germain-en-Laye, Fontainebleau et Versailles, où le chancelier disposait depuis déjà longtemps de logements de fonction à proximité immédiate des châteaux. À Compiègne, un hôtel fut construit pour le chancelier dans les années 1740.

5. Voir sur le sujet: COQUERY Natacha, L'Espace du pouvoir. De la demeure privée à l'édifice public, Paris 1700-1790, Paris, Seli Arslan, 2000.

6. SAINT-SIMON Louis de Rouvroy duc de, Mémoires complets et authentiques du duc de Saint-Simon sur le siècle de Louis XIV et la Régence, Paris, Adolphe Chéruel éditeur, 1856-1858, t. 15, p. 61, disponible en ligne https://gallica.bnf.fr/ark:/12148/bpt6k7050s.texteImage [lien valide en septembre 2021].

7. L'hôtel de Simiane fut construit dans les années 1707-1708 par l'architecte Bullet de Chamblain, pour Michel François Guyhou de Bruslon, un parent neveu par alliance de Bourvallais qui en régla les frais. Le 20 mai 1714, l'hôtel fut vendu pour 40000 livres à Nicolas François, comte de Simiane, chevalier d'honneur de Madame, et époux de Marie Suzanne Guyhou qui n'était autre que la nièce de $\mathrm{M}^{\mathrm{me}}$ de Bourvallais. L'édifice fut ensuite rattaché à l'hôtel de la Chancellerie en 1717 et officiellement acquis par le roi auprès de la famille de Simiane en échange de terres situées en Dauphiné, en 1725. Voir : PAU Clémence, L'Hôtel de Bourvallais. 300 ans de Justice place Vendôme, p. 15.

8. DANGEAU Philippe de Courcillon, marquis de, Journal du marquis de Dangeau Avec les additions inédites $d u$ duc de Saint-Simon. Tome dix-septième 1717-1719, Paris, Eudore Soulié / Louis Dussieux / Charles-Philippe deChennevières-Pointel/ Paul Mantz/ Anatole de Montaiglon et FélixSébastien Feuillet de Conches éditeurs, 1854-1860, p.159, disponible en ligne https:// gallica.bnf.fr/ark:/12148/bpt6k6383072j.texteImage [lien valide en septembre 2021].

9. Nommé chancelier en septembre 1717, Henri-François d'Aguesseau (1668-1751) connut une carrière plus que mouvementée. S'opposant au système de Law, il se vit retirer une première fois la garde des sceaux en janvier 1718 et fut contraint à l'exil, sur ses terres de Fresnes. Il fut rappelé à Paris en 1720 ; les sceaux lui furent rendus jusqu'en 1722, année au cours de laquelle il donna sa démission. Il revint à Paris, après la mort du Régent, en 1727, et y mena d'importantes réformes sur la législation et le système juridique. D'Aguesseau ne prit donc possession de l'hôtel de Bourvallais qu'à son retour à Paris, en juin 1720, après plusieurs années d'exil à Fresnes. Voir : Le Nouveau Mercure, mai 1720, p. 172-173.

10. Terme employé au $\mathrm{XIX}^{\mathrm{e}}$ siècle pour définir les travaux d'agrandissement, d'aménagement intérieur et de décoration d'un bâtiment ancien pour une nouvelle fonction. Voir la définition : «Action d'approprier, de rendre propre à une destination » in Dictionnaire de l'Académie française, Paris, Imprimerie Firmin Didot frères, 1878, $7^{\mathrm{e}}$ édition, t. 1, p. 89, disponible en ligne https:// gallica.bnf.fr/ark:/12148/bpt6k504096/f152.item.texteImage [lien valide en septembre 2021].

11. Rapports de Bénard sur les deux projets d'aménagement du premier étage de l'hôtel du Grand Juge, 25 février 1811, Archives nationales (AN), AF IV, 1357. 
12. PAU Clémence, L'Hôtel de Bourvallais. 300 ans de Justice place Vendôme, p. 44.

13. Rapport au ministre de l'Instruction publique, 21 mars 1946, AN, 19810663, 171.

14. PAU Clémence, L'Hôtel de Bourvallais. 300 ans de Justice place Vendôme, p. 76.

15. AN, $\mathrm{O}^{1} 2221$, fol. 154, cité par: PONS Bruno, De Paris à Versailles. 1699-1736. Les Sculpteurs ornemanistes parisiens et l'art décoratif des bâtiments du roi, Strasbourg, Association les publications près les Universités de Strasbourg, 1986, p. 212.

16. PONS Bruno, De Paris à Versailles. 1699-1736. Les Sculpteurs ornemanistes parisiens et l'art décoratif des bâtiments du roi, p. 212.

17. Élévation de la chambre du Chancellier, 1717-1718, BnF, RESERVE HA18 (6)-FOL, Fonds Robert de Cotte, $n^{\circ} 2316$, disponible en ligne https://gallica.bnf.fr/ark:/12148/btv1b6936702s?rk=21459;2 [lien valide en septembre 2021].

18. PONS Bruno, De Paris à Versailles. 1699-1736. Les Sculpteurs ornemanistes parisiens et l'art décoratif des bâtiments du roi, p. 111.

19. C'est le premier exemple d'un tel traitement du plafond. Voir: KIMBALL Fiske, Le style Louis XV. Origine et évolution du rococo, Paris, Picard et Cie, 1949, p. 138.

20. Commande de portraits des ministres de la Justice et des Cultes pour les salons de la Chancellerie, 1846, AN, BB ${ }^{17} \mathrm{~A}, 146$.

21. Les plans du $\mathrm{XVIII}^{\mathrm{e}}$ de l'hôtel montrent bien la présence d'une cheminée à cet emplacement mais cette dernière n'existait déjà plus sous le Premier Empire.

22. PONS Bruno, «L'Hôtel de la Chancellerie », Monuments historiques, $\mathrm{n}^{\circ} 172$, janvier-février 1991, p. 112 .

23. Lettre de l'architecte Destailleur au directeur des Travaux publics, 17 janvier 1841, AN, $\mathrm{F}^{13} 2349$.

24. DUPLESSIS Georges, Notice sur M. Hippolyte Destailleur, architecte, Paris, Damascène Morgand, 1895 , p. IV. Nous remercions très sincèrement Jean Potel qui nous a communiqué cette précieuse référence.

25. DUPLESSIS Georges, Notice sur M. Hippolyte Destailleur, architecte, Paris, Damascène Morgand, 1895 , p. IV.

26. Discours prononcé devant la Chambre des députés, 1829 , p. 3, note de bas de page $1, \mathrm{AN} \mathrm{BB}^{30}$, 517.

27. DUPLESSIS Georges, Catalogue de livres et estampes relatifs aux beaux-arts, architecture, peinture, gravure, ornementation, etc., provenant de la bibliothèque de feu M. Hippolyte Destailleur, architecte du gouvernement, préface, Paris, Damascène Morgand, 1895, p. V, disponible en ligne https:// gallica.bnf.fr/ark:/12148/bpt6k6489802r.texteImage [lien valide en septembre 2021].

28. Note, circulaires et rapports sur le service de la conservation des monuments historiques, Paris, Imprimerie nationale, 1862, p.124, disponible en ligne https://gallica.bnf.fr/ark:/12148/ bpt6k6377981k.texteImage [lien valide en septembre 2021].

29. FIORI Ruth, L'Invention du Vieux Paris. Naissance d'une conscience patrimoniale dans la capitale, Wavre, Mardaga, 2012, p. 256.

30. Auparavant, cette architecture souffrait d'une certaine négligence, voire d'une indifférence totale, qui fut d'ailleurs à l'origine de la démolition d'un grand nombre d'hôtels aristocratiques de la capitale. Voir: RUTH Fiori, «La Perception de l'architecture classique en France au tournant des $\mathrm{XIX}^{\mathrm{e}}$ et $\mathrm{Xx}^{\mathrm{e}}$ siècles: de la mode d'un style décoratif à la reconnaissance d'un patrimoine national ", in BRUCCULERI Antonio (dir.), Louis Hautecour et la tradition classique, catalogue d'exposition (galerie Colbert, Paris $2^{\mathrm{e}}$ arrondissement, 31 janvier-30 avril 2008), Paris, Institut national d'histoire de l'art, coll. «Catalogues d'exposition», 2008, p. 29, disponible en ligne https://books.openedition.org/inha/2929 [lien valide en septembre 2021].

31. Comme plus largement d'ailleurs des autres places royales de la capitale (place des Vosges, place Dauphine, place des Victoires, place de la Concorde). 
32. S'ils obtinrent gain de cause, la suppression définitive de ces publicités ne fut qu'occasionnelle. Voir: FIORI Ruth, L'Invention du Vieux Paris. Naissance d'une conscience patrimoniale dans la capitale, p. 256.

33. FIORI Ruth, L'Invention du Vieux Paris. Naissance d'une conscience patrimoniale dans la capitale, p. 257.

34. Copie de la lettre du préfet de la Seine au ministre de la Justice au sujet des persiennes de l'hôtel de la Chancellerie, 31 mars 1912, AN, $\mathrm{F}^{21} 6093$.

35. Les persiennes ne furent pas supprimées avant les années 1930.

36. Seul l'hôtel Ritz, au $\mathrm{n}^{\circ} 15$, faisait alors exception : Copie de la lettre du préfet de la Seine au ministre de la Justice au sujet des persiennes de l'hôtel de la Chancellerie, 31 mars 1912, AN, F F $^{21}$ 6093.

37. Extrait du projet de loi $\mathrm{n}^{\circ} 5$ 399, 1918, AN, $\mathrm{F}^{21} 6093$.

38. Lettre du garde des sceaux à la direction des Beaux-Arts, 29 janvier 1919, AN, $\mathrm{F}^{21} 6093$.

39. Lettre $d u$ directeur de cabinet $d u$ garde des sceaux à l'architecte du ministère, 13 janvier 1919, AN, $\mathrm{F}^{21} 6093$.

40. Arrêté des Monuments historiques, 29 décembre 1925, Médiathèque de l'architecture et du patrimoine (ci-après MAP), D/1/75/17.

41. Arrêté des Monuments historiques, 2 mai 1927, AN, $\mathrm{F}^{21} 6093$.

42. Lettre du ministre de l'Instruction publique et des Beaux-Arts certifiant que la façade de l'hôtel du ministère de la Justice sur la place apparaît dans la liste des monuments classés de 1900, 23 mai 1923, MAP, D/1/75/17.

43. Note, circulaires et rapports sur le service de la conservation des monuments historiques, Paris, Imprimerie nationale, 1862, p. 124, disponible en ligne https://gallica.bnf.fr/ark:/12148/ bpt6k6377981k.texteImage [lien valide en septembre 2021].

44. «Liste des monuments classés" in Circulaires ministérielles relatives à la conservation des monuments historiques, Paris, Imprimerie nationale, 1875, p.70, disponible en ligne https:// mediatheque-patrimoine.culture.gouv.fr/sites/mediatheque/files/documents/liste_mh_1875.pdf [lien valide en septembre 2021].

45. Loi pour la conservation des monuments et objets d'art ayant un intérêt historique et artistique, 30 mars 1887, p. 1531.

46. Note de Jacques Dupont, architecte en chef des monuments historiques, sur les décors Second Empire de l'hôtel du ministère de la Justice, 4 mars 1952, MAP, D/1/75/17.

47. Note de Jacques Dupont, architecte en chef des monuments historiques, sur les décors Second Empire de l'hôtel du ministère de la Justice, 4 mars 1952, MAP, D/1/75/17.

48. Note de Jacques Dupont, architecte en chef des monuments historiques, sur les décors Second Empire de l'hôtel du ministère de la Justice, 4 mars 1952, MAP, D/1/75/17.

49. Note de Jacques Dupont, architecte en chef des monuments historiques, sur les décors Second Empire de l'hôtel du ministère de la Justice, 4 mars 1952, MAP, D/1/75/17.

50. THOMINE-BERRADA Alice, «L'Histoire de l'architecture du XIX ${ }^{\mathrm{e}}$ siècle en France, regard sur la création d'un champ de recherche et son renouvellement ", Livraisons de l'histoire de l'architecture, $\mathrm{n}^{\circ} 21,2011$, p. 79-88, disponible en ligne https://journals.openedition.org/lha/277 [lien valide en septembre 2021].

51. Arrêté du 4 novembre 1952, MAP, D/1/75/17.

52. Fiche de recensement des monuments anciens de la France, ministère de la Justice, 11-13 place Vendôme, 18 mai 1977, MAP, D/1/75/17.

53. Cette double rangée de lucarnes fut réalisée dans les années 1950-1960 alors que la toiture du bâtiment était déjà inscrite sur l'Inventaire supplémentaire des monuments historiques. Voir : Procès-verbal de la séance du 28 novembre 1977, MAP, D/1/75/17.

54. Arrêté du 22 février 1980, MAP, D/1/75/17. 
55. Au premier étage sur la place: le grand salon, la salle à manger le boudoir ; au rez-dechaussée sur le jardin : le salon d'angle, la salle des Sceaux, la bibliothèque ; au premier étage sur le jardin: le salon d'angle, le second salon, le salon des Portraits, ainsi que la salle à manger d'apparat.

56. Arrêté du 23 juin 1988, MAP, D/1/75/17.

57. Arrêté du 7 novembre 1991, MAP, D/1/75/17.

\section{RÉSUMÉS}

L'hôtel de Bourvallais, situé aux $\mathrm{n}^{\text {os }} 11$ et 13 de la place Vendôme, occupe une place toute particulière dans l'histoire des institutions françaises : depuis 1718 , il n'a jamais cessé d'abriter la Chancellerie de France puis le ministère de la Justice et ce, en dépit des révolutions et des coups d'État qui ont marqué l'histoire de France. Exemple remarquable de la pérennité des lieux de pouvoir dans la capitale, l'hôtel du ministère constitue également un patrimoine exceptionnel pour la Justice : à travers le processus de patrimonialisation de l'hôtel de Bourvallais, aujourd'hui classé au titre des Monuments historiques, nous nous proposons donc de revenir sur l'histoire de cet édifice emblématique qui a connu, en trois siècles d'occupation continue, de très nombreuses transformations. Cette approche patrimoniale permettra de mettre en évidence les différents aménagements de l'hôtel, ainsi que ces décors datant principalement du XIX siècle, et qui constituent de nos jours l'incroyable témoignage de plus de 300 ans de Justice, place Vendôme.

The hôtel de Bourvallais, located at $\mathrm{n}^{\circ} 11$ and 13 place Vendôme, holds a very special place among the French institutions' history: since 1718, it never ceased to host the French Chancellery, then ministry of Justice, despite the revolutions and overturns that marked French history. Outstanding example of the sustainability of power places in Paris, the ministry hotel also constitutes an exceptional heritage for the Department of Justice. Through the patrimonialization process of the hôtel de Bourvallais, today listed historical monument, we propose to revisit the history of the iconic building which has undergone, during three centuries of continued occupation, many transformations. This heritage approach will also highlight the various hotel facilities and his interior decoration, mostly dating from the nineteenth century, which are nowadays an incredible testament of more than 300 years of Justice in place Vendôme.

\section{INDEX}

Keywords : mansion, ministry, heritage, justice, chancellery, Bourvallais, decoration, historic monument

Mots-clés : hôtel, ministère, patrimoine, justice, chancellerie, Bourvallais, décor, monument historique

\section{AUTEUR}

\section{CLÉMENCE PAU}

Doctorante à Sorbonne-Université 
clemencepau94@gmail.com 